\title{
Investigation on Granular Medium Forming Formability of TA1 Titanium Alloy Cylinder-Shaped Parts
}

\section{Biao Hu}

Zhejiang Sci-Tech University

Gaoshen Cai ( $\nabla$ caigaocan@zstu.edu.cn )

Zhejiang Sci-Tech University

Jubo Fu

Zhejiang Sci-Tech University

Yanxi Xin

Zhejiang Sci-Tech University

Kangning Liu

Beihang University

Lihui Lang

Beihang University

\section{Research Article}

Keywords: TA1 titanium alloy, granular medium forming, numerical simulation

Posted Date: June 3rd, 2021

DOI: https://doi.org/10.21203/rs.3.rs-564767/v1

License: (1) This work is licensed under a Creative Commons Attribution 4.0 International License. Read Full License

Version of Record: A version of this preprint was published at The International Journal of Advanced Manufacturing Technology on September 24th, 2021. See the published version at https://doi.org/10.1007/s00170-021-08108-w. 


\title{
Investigation on Granular Medium Forming Formability of TA1 Titanium Alloy Cylinder-shaped Parts
}

\author{
Biao Hu ${ }^{1}$, Gaoshen Cai ${ }^{1,2,}$, Jubo Fu ${ }^{1}$, Yanxi Xin ${ }^{1}$, Kangning Liu ${ }^{3}$ and Lihui Lang ${ }^{3}$ \\ ${ }^{1}$ Faculty of Mechanical Engineering \& Automation, Zhejiang Sci-Tech University, Hangzhou \\ 310018, China; \\ hoobil@163.com (H.B.); fujubo598@163.com (J.F.); wy2201498446@163.com (Y.X.) \\ ${ }^{2}$ Key Laboratory of Advanced Manufacturing Technology of Zhejiang Province, \\ School of Mechanical Engineering, Zhejiang University, Hangzhou 310027, China \\ ${ }^{3}$ School of Mechanical Engineering and Automation, Beihang University, Beijing 100191, China; \\ 1kn_buaa@163.com (K.L.); lang@buaa.edu.cn (L.L.) \\ ${ }^{*}$ Correspondence: caigaocan@zstu.edu.cn; Tel.: +86-0571-868-43343
}

\begin{abstract}
In order to investigate the formability of the granular medium forming (GMF), based on the Mohr-Coulomb constitutive model with the tri-axial compression test of granular medium and the true stress-strain curves of TA1 titanium alloy from uniaxial tensile tests, the numerical simulation of TA1 titanium alloy sheet deep drawing with finite element method was performed, and the deep drawing tests were also carried out. Simulation analysis and test results show that the GMF process is suitable for titanium alloy sheets, and can effectively improve the uniformity of the wall thickness of the formed parts, reduce the tendency of wrinkles and improve the forming quality.
\end{abstract}

Keywords: TA1 titanium alloy; granular medium forming; numerical simulation

\section{Introduction}

At present, with the wide application of lightweight components in aviation, aerospace, automobile, energy and other fields, more and more high requirements are put forward for the advanced forming technology of lightweight alloy thin-walled parts. There are many limitations in the existing processing methods, which can not meet the increasingly demanding processing requirements. In order to solve this problem, research institutions of various countries have proposed a variety of processes to 
improve the forming quality of lightweight parts ${ }^{[1-4]}$.

The GMF process, which uses granules as a pressure-transfer medium in order to form a workpiece, is a newly proposed flexible die-forming technique ${ }^{[5-9]}$. Because the application of this process can fully exploit recent advances in the formability of lightweight materials at elevated temperatures, as well as overcome the limitations that the heat-resistant oil used in warm hydroforming operations can withstand temperatures of no more than $350^{\circ} \mathrm{C}^{[10-12]}$ and that the inert gas used at higher temperatures in hot pneumatic bulging processes usually causes leakage problems ${ }^{[13,14]}$, the GMF process has recently attracted considerable attention by several researchers ${ }^{[15-18]}$.

The principle of the GMF technology is shown in Figure 1. A sheet is placed on the concave die; The charging barrel is pressed on the sheet, thus playing the role of edge pressing and sealing; Then the granular medium is loaded into the charging barrel, and pressure is applied to the convex die block, so that the granular forming pressure under the pressure of the block, which are transferred to the sheet through the granular; The middle part of sheet firstly produce plastic deformation because it is subjected to the action of bidirectional tensile stress under the action of forming pressure, and then the flange material gradually enters the die under the action of radial tensile stress, and finally the sheet is completely attached to the die and formed into the cavity shape of the $\mathrm{die}^{[5]}$.

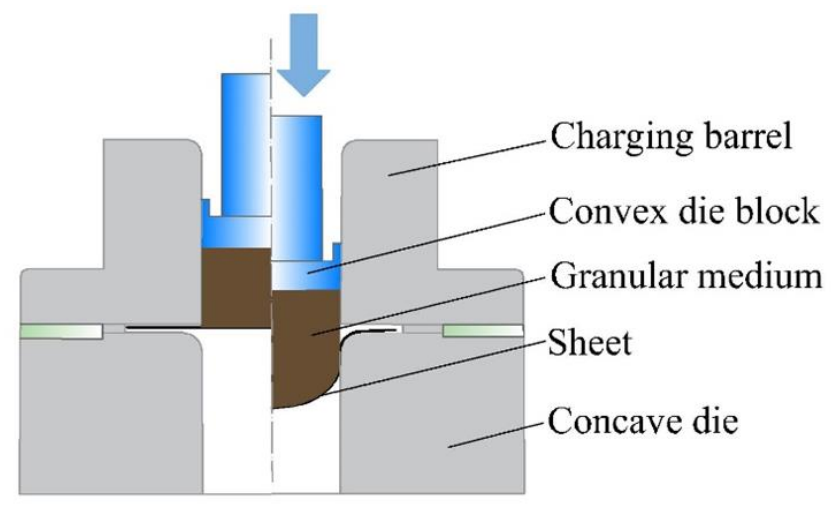

Fig. 1 Schematic of granular medium forming process

Cylinder-shaped part is the most classic and the most representative part, which can well show the uniformity of wall thickness and wrinkle phenomenon of parts. Many researchers take cylinder-shaped parts as the research object to study the forming 
process formability. Zhao ${ }^{[19]}$ et al. conducted an experimental study on the granular soft die deep drawing of cylinder-shaped parts, and found that the thickness of each part of the forming parts decreased and the thinning amount increased with the increase of the depth of the drawing. Chen ${ }^{[20]}$ et al. took cylinder-shaped parts as the research object, and studied the influence of liquid chamber pressure loading path, forming liquid chamber pressure, blank holder force and blank holder clearance on the sheet hydroforming effect. It is found that the reasonable pressure loading path and blank holder gap of the liquid chamber can effectively control the wrinkle in the flange area of the part and prevent the punch from cracking. At present, the researchers mainly used the cylinder-shaped parts to study the hydroforming process and the granular soft die forming process formability, however, very few investigation concentrates on the GMF process formability, which is a main target of this research.

To study the formability of the GMF process, this paper takes cylinder-shaped parts as the research object, and carries out the simulation calculation and experimental verification of its forming process. In order to improve the accuracy of simulation calculation, the Mohr-Coulomb constitutive model with the tri-axial compression test of granular medium and the mechanical property data of TA1 titanium alloy sheet obtained by uniaxial tensile test were used as the required parameters of the simulation model.

\section{Material Formability Test}

\subsection{Tri-axial Compression Test of Granular Medium}

In order to explore the flow and deformation characteristics of granular medium in the forming process, domestic and foreign scholars have used a variety of measurement methods, including axial static pressure transmission formability test, direct shear test and so on ${ }^{[5,16]}$, however, these methods are unable to reflect the dynamic flow properties of the material during the compression deformation process, and its applicability is not good for the GMF process. The tri-axial compression test, which is a relatively mature geotechnical test method, is suitable for measuring the dynamic compression deformation characteristics of granular materials under the condition of triaxial compressive stress. Therefore, in order to determine the parameters of the Mohr- 
Coulomb model of granular materials, the tri-axial compression test is selected to determine the deformation characteristics and pressure transmission laws of granular materials.

When the Mohr-Coulomb strength theory index is obtained by using the tri-axial compression test, the Mohr circle of stress when the material fails (or yields) under different confining pressure levels should be drawn, then the outer circle of different Mohr circle of stress is the shear strength line of the geotechnical material. In threedimensional stress space, the yield surface of Mohr-Coulomb strength theory is a hexagonal pyramid with hydrostatic stress line as symmetry axis (Figure 2), and its intersection line with the $\pi$ plane is not a regular hexagon inscribed to the Mises circle. In addition, it should be noted that the positive direction of each coordinate axis is the direction of compressive stress, which is opposite to the symbol in the calculation of metal plastic deformation. In the three-dimensional stress space, the Mohr-Coulomb yield surface function is expressed as follows ${ }^{[21]}$ :

$$
\begin{aligned}
& F=R_{m c} q-p \tan \varphi-c=0 \\
& R_{m c}(\Theta, \varphi)=\frac{1}{\sqrt{3} \cos \varphi} \sin \left(\Theta+\frac{\pi}{3}\right)+\frac{1}{3} \cos \left(\Theta+\frac{\pi}{3}\right) \tan \varphi
\end{aligned}
$$

Where $\varphi, c$ are the internal friction angle and cohesion of the material respectively, $\Theta$ are the polar deflection angles of the stress state point of the material in the $\pi$ plane, and $\mathrm{p} 、 \mathrm{q} 、 \mathrm{r}$ are the invariants of the first, second, and third stress states respectively:

$$
\begin{aligned}
& p=\operatorname{trace}(\sigma) \\
& q=\sqrt{3 / 2 S: S} \\
& r=\sqrt[3]{9 / 2 S S: S}
\end{aligned}
$$

$$
S=\sigma+p I
$$

The parameters of Mohr-Coulomb model obtained by tri-axial compression test are shown in Figure 3. It can be seen from the figure that the Mohr-Coulomb friction model of non-metallic granular material selected in this paper has good fluidity and can effectively transfer the forming deep drawing force with the cohesion $C=1.6255 \mathrm{kPa}$ 
and the internal friction Angle $\varphi=14.9352^{\circ}$.

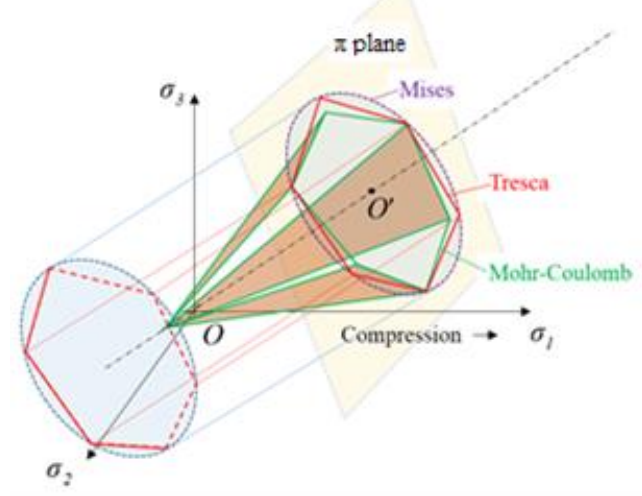

Fig. 2 Mohr-Coulomb yield surface in 3D stress space tests

2.2 High-temperature Uniaxial Tensile Test of TA1 Titanium Alloy

In order to obtain the tensile property of titanium alloy TA1 material at high temperature, the high temperature uniaxial tensile test was carried out on the sheet of titanium alloy TA1 with the thickness of $1.0 \mathrm{~mm}$. The test was conducted on ZWICK unidirectional tensile testing machine of Shougang Research Institute. The effective heating length of the furnace was $300 \mathrm{~mm}$, and the clamping scheme of superalloy pin was adopted. High temperature uniaxial tensile tests were carried out at same temperatures $\left(500^{\circ} \mathrm{C}\right)$ and at different strain rates $\left(0.1 \mathrm{~s}^{-1}, 0.02 \mathrm{~s}^{-1}, 0.005 \mathrm{~s}^{-1}\right)$.

The uniaxial tensile specimen used in the test generally has a rectangular section and a certain length of parallel section. The strain value of sheet specimen in the deformation process can be measured by using an extensometer clamped in the width and length direction of uniaxial tensile specimen, and then the stress can be calculated by obtaining the real-time tension at both ends of the tensile testing machine ${ }^{[22-23]}$. However, the accuracy of the stress and strain measurement method is based on the deformation uniformity of the specimen. When the uniaxial tensile specimen exhibits dispersive instability (necking), the measured stress-strain curve will have errors. Therefore, the extensometer measurement method can only obtain the material flow stress variation before necking. For sheet metal plastic deformation process, especially the forming process of bulging and deep drawing with the characteristics of two-way drawing deformation, the ultimate strain of the material in the uniform deformation stage is often much larger than the strain value in uniaxial tensile test. In the simulation 
analysis of forming process, if the material mechanical behavior before necking obtained by uniaxial tensile test is used as the basis to predict the plastic deformation process of sheet metal, a large error will be generated. In order to obtain the accurate stress-strain curve of titanium alloy TA1 material after necking, a reverse modeling algorithm which is based on FEA method proposed by Lang ${ }^{[24]}$ et al. was adopted in this paper. The reverse modeling process flow chart is shown in Figure 4. Figure 5 shows the stress-strain curves optimized by iterative steps in reverse modeling at different strain rates $\left(0.005 \mathrm{~s}^{-1}, 0.02 \mathrm{~s}^{-1}, 0.1 \mathrm{~s}^{-1}\right)$. It can be seen that, under the condition of $500^{\circ} \mathrm{C}$, the lower the strain rate, then the higher the maximum elongation, however, different strain rates have no significant effect on the hardening curve.

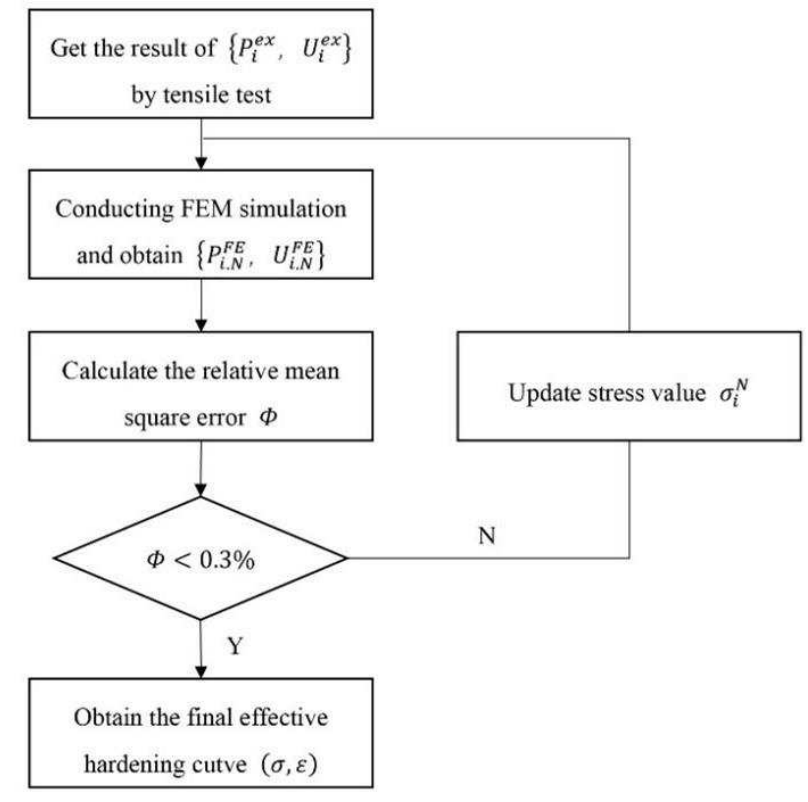

Fig. 4 Schematic diagram of the inverse method ${ }^{[24]}$

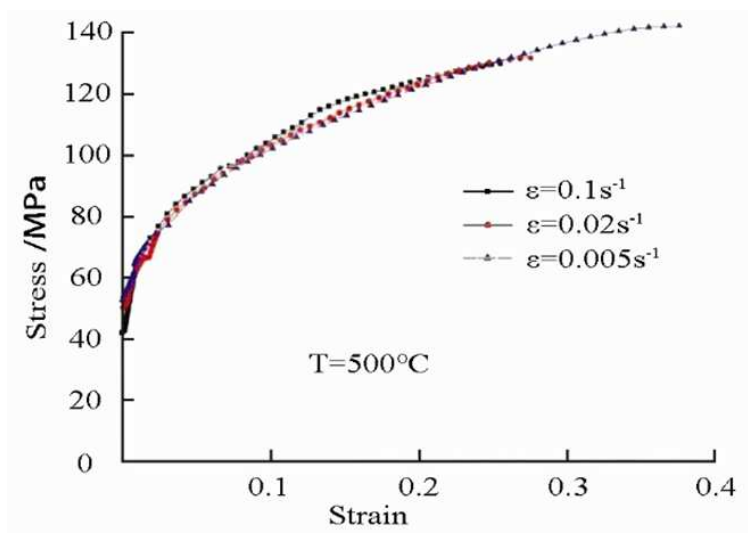

Fig. 5 True stress-strain curves of TA1 sheet under different conditions

To further study the strength and fracture failure mechanism of the material, the 
microstructure of uniaxial tensile specimens under different temperature conditions (normal temperature, $500^{\circ} \mathrm{C}, 550^{\circ} \mathrm{C}, 600^{\circ} \mathrm{C}$ ) was analyzed by $\mathrm{SEM}$ in this paper. The observation results of SEM were shown in Figure 6. It is obvious that the uniaxial tensile fracture morphology of titanium alloy TA1 has a large number of dimples and holes distribution in all temperature ranges, indicating that the fracture process of titanium alloy TA1 appeared microscopic pore nucleation, growth and polymerization deformation mechanism. Figure 6a shows that the fracture tearing morphology at room temperature. Under such temperature conditions, the dimples of titanium alloy TA1 in uniaxial tensile fracture are many and small, and the dimples are shallow, which is a typical character for microporous aggregated ductile fracture. With the increase of temperature (Figure 6b, Figure 6c), the number of dimple holes decreases and the depth increases, indicating that with the increase of temperature, the plasticity of titanium alloy TA1 material increases, the nucleation rate of microholes decreases and the toughness increases.

\section{Numerical Simulation of GMF Process for Cylinder-shaped Parts}

\subsection{Numerical Simulation of GMF Process}

The thickness uniformity of the parts formed by the traditional hot stamping process is poor, and wrinkles are prone to occur, so it is difficult to meet the processing needs of the cylinder-shaped parts. The optimum forming temperature of titanium alloy is generally higher than $500^{\circ} \mathrm{C}$, while the highest heat-resistant temperature of heat transfer oil does not exceed $350^{\circ} \mathrm{C}$. Therefore, the hydraulic oil widely used in the conventional liquid-filled forming process no longer meets the requirements of titanium alloy thermal medium forming, and low melting point alloy, viscous medium or nonmetallic ceramic particles must be used as the forming medium. In consideration of safety and sealing, non-metallic ceramic particles are selected as the force transmission medium.

Figure 7 shows a schematic diagram of the GMF process, where a fluid granular medium to replace the rigid punch. During the forming process, the flexible punch continuously changes the contour of the bottom along with the deformation of the material, thereby ensuring that the plate maintains proper normal stress support in the 
thickness direction, reducing the tendency of wrinkling and improving the formability.

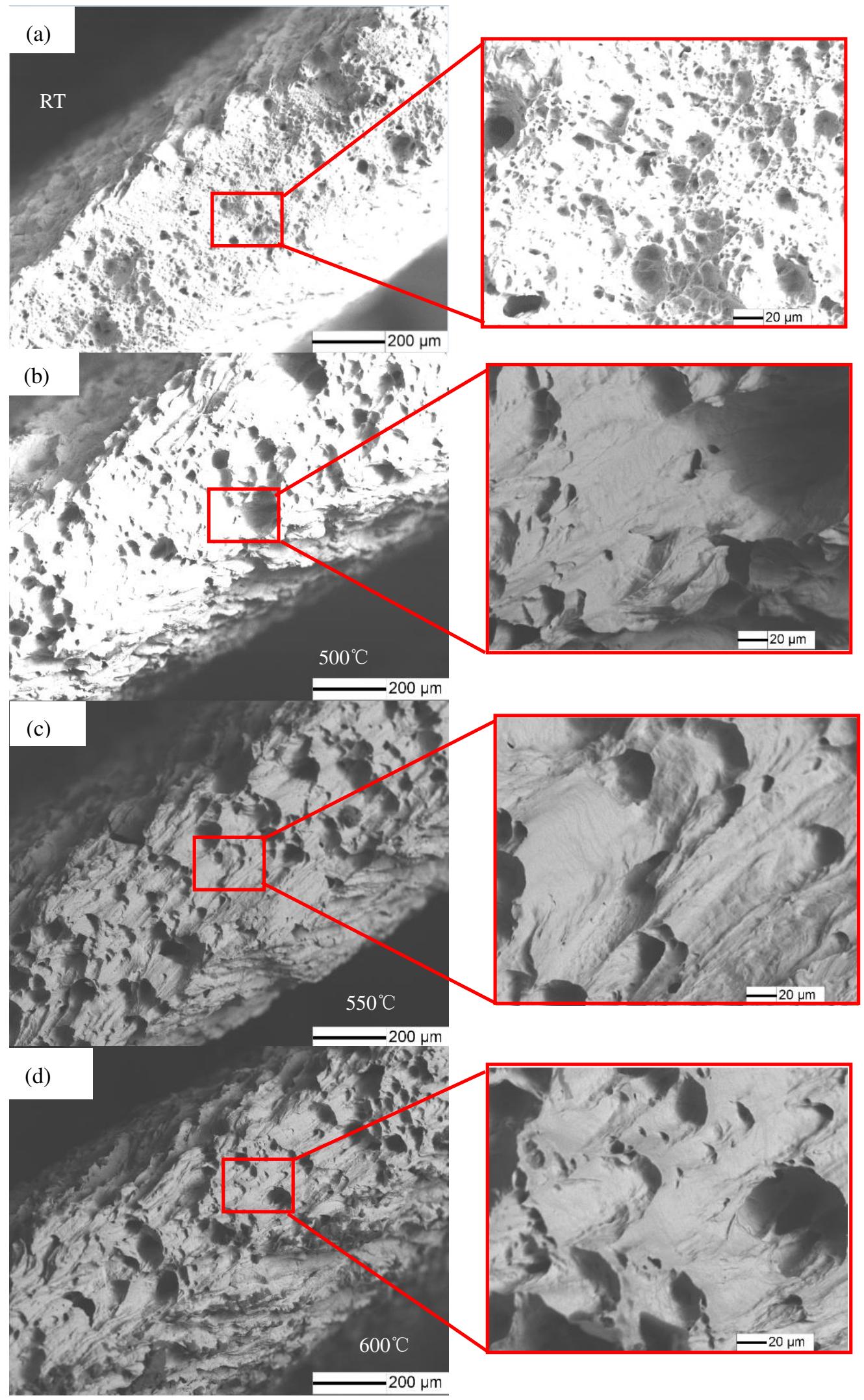

Fig. 6 Fracture morphology of TA1 specimen after tensile test 


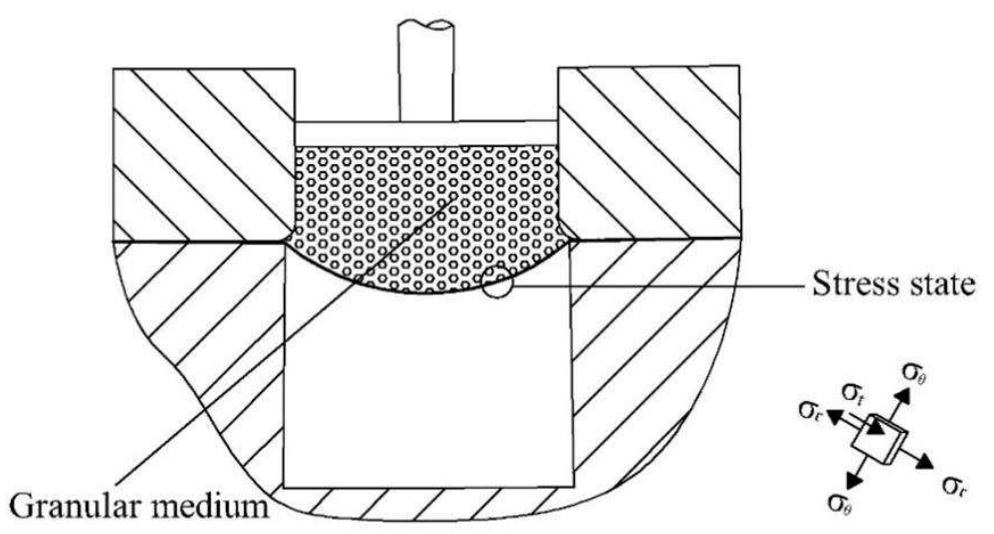

Fig. 7 Diagram of the process of deep drawing with granular medium

In this paper, the material parameters of titanium alloy obtained from hightemperature uniaxial tensile test and the pressure transfer parameters of granular medium obtained from tri-axial compression test were used to establish the calculation model of the GMF process as shown in Figure 8 . The thickness of TA1 plate is $1 \mathrm{~mm}$, the test temperature is selected as $500^{\circ} \mathrm{C}$, and the fixed gap between blank holder and die is $1.2 \mathrm{~mm}$. The cavity in the central part of the blank holder is filled with liquid granular material with particle size of $0.117 \mathrm{~mm} \sim 0.14 \mathrm{~mm}^{[25]}$.

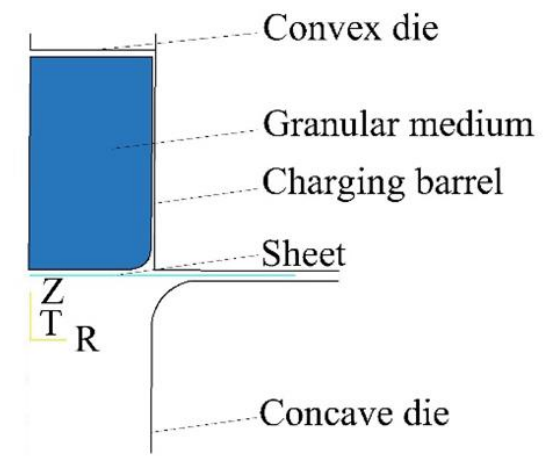

Fig. 8 Numerical model of the granular medium forming process

\subsection{Analysis of Simulation Results}

The calculation and analysis results are shown in Figure 9. It can be seen that under the conditions of different billet diameters $(160 \mathrm{~mm}, 180 \mathrm{~mm})$ and different forming heights $(42.5 \mathrm{~mm}, 44 \mathrm{~mm}, 58.3 \mathrm{~mm}, 81 \mathrm{~mm})$, the forming parts all show good forming formability.

It can also be seen that during the GMF process, the minimum wall thickness appears in the central area of the pass bottom, and the wall thickness value increases 
uniformly from this area to the edge of the part. The formed part has good uniformity of wall thickness, and its maximum thinning rate is only $18 \%$.

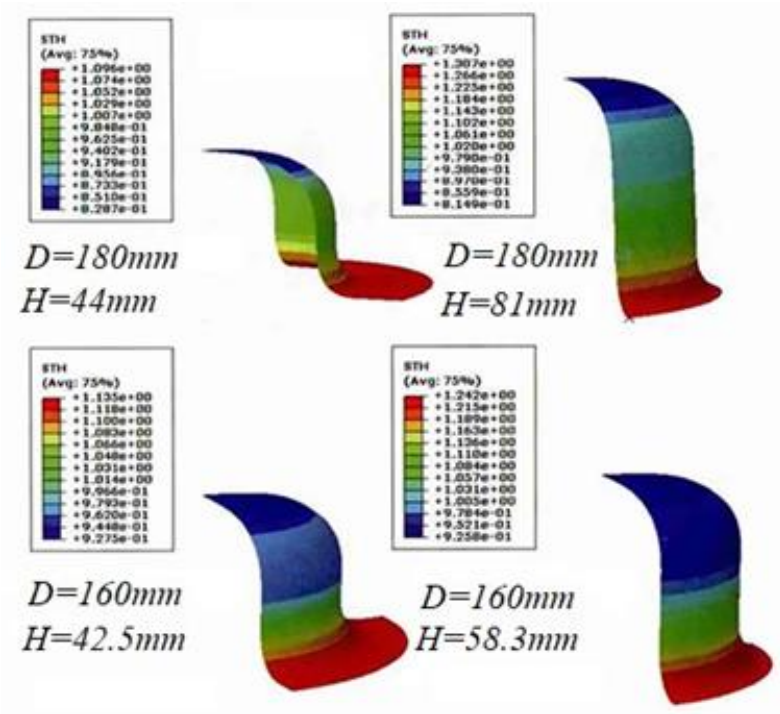

Fig. 9 Results of numerical simulation

\section{High-temperature Granular Medium Test of TA1 Titanium Alloy Cylinder-} shaped Part

\subsection{Experimental Equipment and Material}

In order to evaluate the accuracy of simulation calculation of the GMF process, the high-temperature GMF experiment was carried out on YRJ-50 sheet metal experimental machine independently developed by Beijing University of Aeronautics and Astronautics. The inner diameter of charging barrel is $80 \mathrm{~mm}$, the inner diameter of the die is $85 \mathrm{~mm}$, the thickness of TA1 titanium alloy sheet is $1 \mathrm{~mm}$, and the blank holder clearance is $1.2 \mathrm{~mm}$. The diagram of the high-temperature GMF test die is shown in Figure 10. Under the condition of $500^{\circ} \mathrm{C}$, TA1 titanium alloy sheet with blank diameter of $160 \mathrm{~mm}$ and $180 \mathrm{~mm}$ was formed with different depth of drawing.

Under the condition of high-temperature, colloid graphite water agent are selected as lubricant, which smear on the surface of the blank and wait for drying. Graphite water agent not only plays the role of lubrication, but also can effectively prevent oxidation on the surface of titanium alloy plate under high-temperature conditions. The forming process is controlled by constant drawing rate, and the drawing rate is $5 \mathrm{~mm} / \mathrm{min}$. 


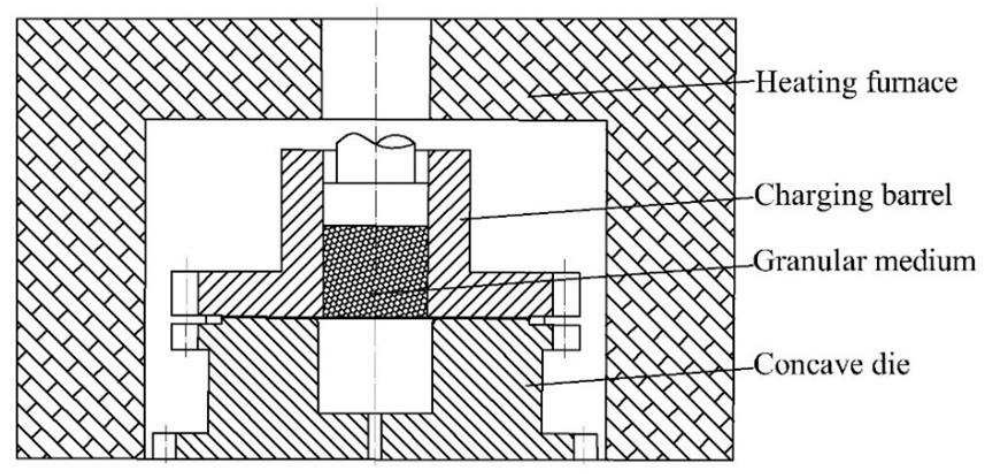

Fig. 10 Diagram of experimental equipment for hot granular medium forming

\subsection{Part Forming Process Analysis}

The parts formed under the condition of master cylinder pressure of 40 tons of equipment are shown in Figure 11. It can be seen that the surface of the formed parts is smooth without wrinkling. The three-dimension coordinate measurement and the measurement of the wall thickness distribution of the parts with forming height $\mathrm{H}=58.3 \mathrm{~mm}$ and $\mathrm{H}=81.5 \mathrm{~mm}$ were carried out, and the results were compared with the simulation results. The comparison results under corresponding forming conditions are shown in Figure 12. It can be seen from the figure that the test data points are in good agreement with the simulation curve, reflecting that the material parameters obtained from the tri-axial compression test and high-temperature uniaxial tensile test can accurately characterize the flow deformation law of granular medium and TA1 titanium alloy sheet under high temperature conditions, as well as the accuracy of the simulation results.

It is obviously observed from Figure 12a that the bottom contour of the part is an arc surface under high-temperature conditions and the curvature of the bottom contour of the part keeps increasing and finally fits with the concave die surface with the increasing of the depth of drawing. According to the distribution curve of the bottom wall thickness of the part shown in Figure 12b, the minimum bottom central wall thickness of the part forming height of $58.3 \mathrm{~mm}$ and $81.5 \mathrm{~mm}$ is $0.92 \mathrm{~mm}$ and $0.80 \mathrm{~mm}$ respectively. Combined Figure 12a with Figure 12b, it can be seen that the deformation characteristics of the blank in the granular medium forming process are different from those in the active liquid filling/air expanding forming process. The blank deformation of the GMF process is not achieved by thinning and deep drawing. The forming process 
is accompanied by the flow of the blank, so that the plate has a more uniform wall thickness distribution.

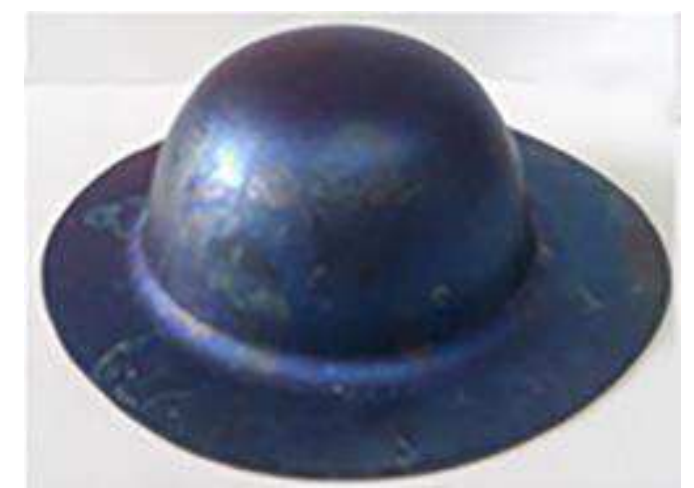

Fig. 11 Fabricatd TA1 part by GMF method at $500^{\circ} \mathrm{C}$

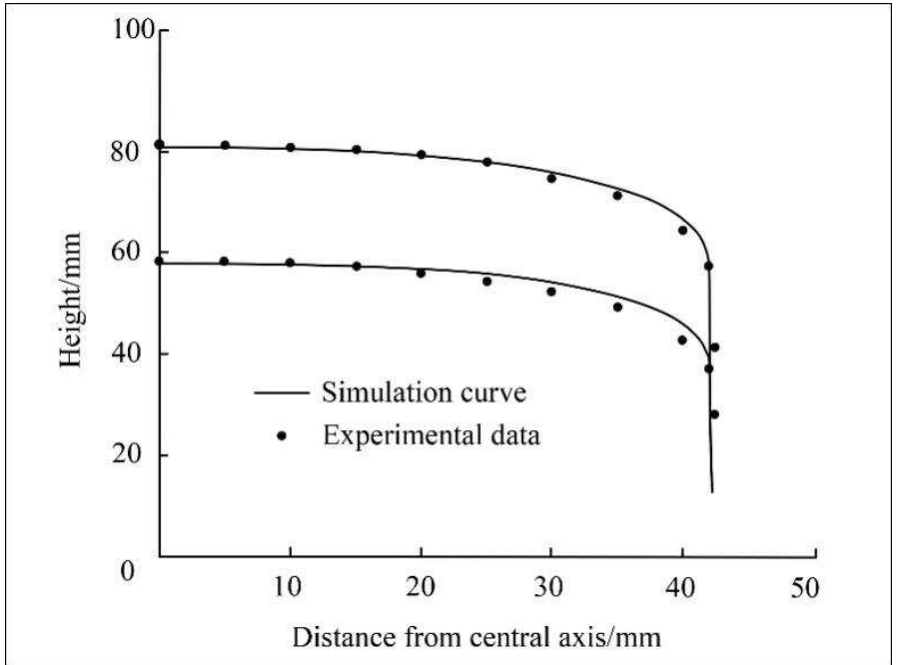

(a) Comparison of shape dimension between numerical simulation and experimental results

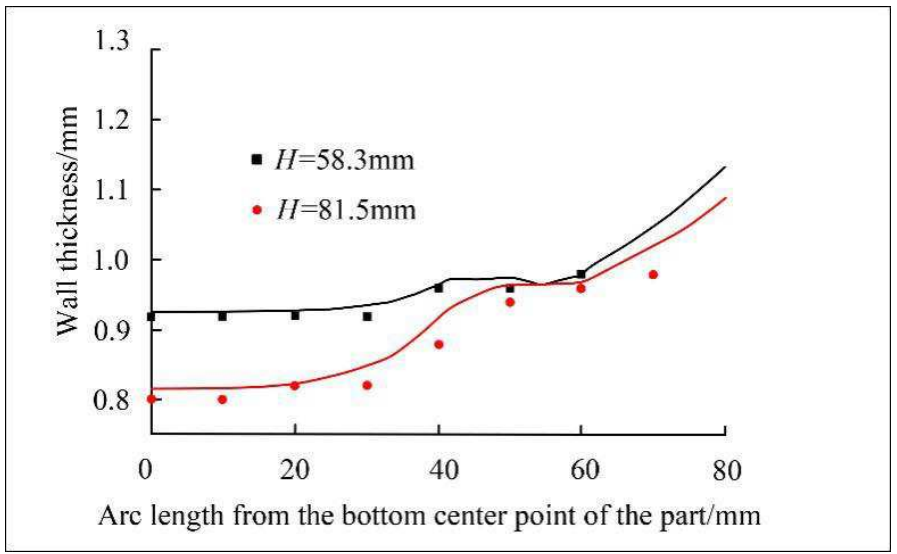

(b) Comparison of thickness distribution between numerical simulation and experimental results

Fig. 12 Comparison of shape dimension and thickness distribution between numerical simulation and experimental results

\section{Conclusions}


Using a combination of numerical simulation and experimental verification, a GMF experiment was conducted on titanium alloy sheets in order to investigate and verify the formability of granular medium forming. The main conclusions were summarized as follows.

(1) The GMF technology using granular instead of rigid die can achieve hightemperature processing forming of titanium alloy parts, and forming temperature can reach more than $500^{\circ} \mathrm{C}$.

(2) The results of simulation and experiment show that the cylinder-shaped parts of titanium alloy formed by the GMF process have good uniformity of wall thickness.

(3) Under the action of compressive stress in the thickness direction, the wrinkling tendency of titanium alloy parts is effectively suppressed and the forming quality is improved.

Funding: This research was funded by the Key Laboratory of Advanced Manufacturing Technology of Zhejiang Province, Grant No. 2020KF06, Zhejiang Provincial Natural Science Foundation of China, Grant No. LQ18E050010, and the Scientific Research Foundation of Zhejiang Sci-Tech University, Grant No. 17022073-Y.

Conflicts of Interest: The authors declare no conflict of interest.

Availability of data and material: All the data presented and/or analyzed in this study are available upon request to the corresponding author.

Code availability: Not applicable.

Ethical approval: Not applicable.

Consent to participate: Not applicable.

Consent to publish: The author agrees to publication in the International Journal of Advanced Manufacturing Technology and confirms that the work described has not been published before, and its publication has been approved by all co-authors.

Author Contributions: Conceptualization, G.C., B.H., and K.L.; methodology, G.C., K.L., B.H., and L.L.; software, J.F., Y.X., and K.L.; experiments, B.H. and K.L.; validation, G.C., B.H., and K.L.; formal analysis, G.C., B.H., and L.L.; investigation, J.F.; resources, G.C.; data curation, Y.X.; writing — original draft preparation, B.H. and G.C.; writing—review and editing, G.C., B.H., 
and J.F.; visualization, L.L.; supervision, Y.X.; project administration, J.F.; funding acquisition, G.C.

\section{Reference}

[1] Lang LH, Liu KN, Cai GS, Guo C (2013) Numerical Research on Forming Technology of Complicated Taper-Shaped Part of TC4 Titanium Alloy by Thermal Deep Drawing With Heated Media. Aeron Manuf Technol (16):109-112. https://doi.org/10.16080/j.issn1671-833x.2013.16.025

[2] Cao MY, Zhao CC, Dong GJ, Hao BH (2013) Mechanical Analysis of Deep Drawing of Cylinder Based on Solid Granules Medium Forming Technology. Chin J Mech Eng 49(02): 42-48

[3] Cai GS, Liu KN, Liu BS, Du PM (2011) Numerical simulation analysis of warm hydroforming process for special aluminum-alloy part. Forg Stamp Techno 36(06):129132

[4] Khodayari G (2009) Bending Limit Curve for Rotary Draw Bending of Tubular Components in Automotive Hydroforming Applications. SAE Int J Mater Manf 1(01):841-848. https://doi.org/10.4271/2008-01-2762

[5] Zhao CC, Li XD, Dong GJ, Wang YS (2009) Solid granules medium forming technology and its numerical simulation. Chin J Mech Eng 45:211-215. https://doi.org/10.3901/JME.2009.06.211

[6] Zhao CC, Wang YS, Li XD, Dong GJ, Liu SB (2007) Solid granules medium forming technology and theoretical research. Plast Eng 14(03):54-59

[7] Dong GJ, Zhao CC, Cao MY (2013) Flexible-die forming process with solid granule medium on sheet metal. Trans Nonferr Metals Soc China 23(09):2666-2677. https://doi.org/10.1016/S1003-6326(13)62783-1

[8] Liu KN, Lang LL, Zhang WS, Marai M, Liu BS (2017) Coupled EulerianLagrangian simulation of granular medium sheet forming process and experimental investigation at elevated temperature. Int J Adv Manuf Technol 88:2871-2882. https://doi.org/10.1007/s00170-016-8996-3

[9] Du B, Zhao CC, Dong GJ, Bi J (2017) FEM-DEM coupling analysis for solid granule medium forming new technology. J Mater Process Tech. 249:108-117. https://doi.org/10.1016/j.jmatprotec.2017.05.024 
[10] Lang LL, Liu BS, Li T, Zhao XN, Zeng YS (2012) Experimental investigation on hydromechanical deep drawing of aluminum alloy with heated media. Steel Res Int 83(03):230-237. https://doi.org/10.1002/srin.201100231

[11] Turkoz M, Cora ON, Gedikli H, Dilmec M, Halkaci HS, Koc M (2020) Numerical optimization of warm hydromechanical deep drawing process parameters and its experimental verification. Manuf Process 57:344-353. https://doi.org/10.1016/j.jmapro.2020.06.020

[12] Cai GS, Yang JL, Yuan YF, Yang XY, Lang LH, Alexandrov S (2020) Mechanics analysis of aluminum alloy cylindrical cup during warm sheet hydromechanical deep drawing. Int J Mech Sci 174:105556. https://doi.org/10.1016/j.ijmecsci.2020.105556

[13] Cai GS, Fu JB, Zhang DX, Yang JL, Yuan YF, Lang LH, Alexandrov S (2020) A novel approach to predict wrinkling of aluminum alloy during warm/hot sheet hydroforming based on an improved Yoshida buckling test. Materials 13(05):1165. https://doi.org/10.3390/ma13051165

[14] Dasappa P, Inal K, Mishra R (2012) The effects of anisotropic yield functions and their material parameters on prediction of forming limit diagrams. Int J Solids Struct 49(25):3528-3550. https://doi.org/10.1016/j.ijsolstr.2012.04.021

[15] Qiu G, Henke S, Grabe J (2011) Application of a Coupled Eulerian-Lagrangian approach on geomechanical problems involving large deformation. Comput Geotech 38:30-39. https://doi.org/10.1016/j.compgeo.2010.09.002

[16] Grüner M, Merklein M (2010) Numerical simulation of hydroforming at elevated temperatures with granular material used as medium compared to the real part geometry. Int J Mater Form 3:279-282. https://doi.org/10.1007/s12289-010-0761-9

[17] Chen H, Güner A, Ben Khalifa N, Tekkaya AE (2016) Granular media-based tube press hardening. J Mater Process Technol 228:145-159. https://doi.org/10.1016/j.jmatprotec.2015.03.028

[18] Cai GS, Fu JB, Wu CY, Liu, KN, Lang LH (2021) Simulation and Experimental Investigation of Granular Medium Forming Technology on Titanium Alloy Sheet at 500॰C. Metals 11(01):114. https://doi.org/10.3390/met11010114

[19] Zhao ZY, Luo JT, Huang QY, Wang CW, Zhang CX (2013) Experimental Research on Deep Drawing of Cup Shell by Granules Flexible Cavity Forming. Chin Mech Eng 
24(10):1395-1398.

[20] Chen XG, Li JG, Zhang JG, Tian S (2015) Numerical Simulation of 2A12 Aluminum Flat Bottom Cylindrical Part by Hydromechanical Deep Drawing. Journal of Netshape Forming Engineering 7(06):86-91.

[21] Liu KN, Lang LH, Zhang WS, Marai M, Liu BS (2017) Coupled EulerianLagrangian simulation of granular medium sheet forming process and experimental 1nvestigation at elevated temperature. Int J Adv Manuf Technol 88 : 2871-2882. https://doi.org/10.1007/s00170-016-8996-3

[22] Coppieters S, Kuwabara T (2014) Identification of post-necking hardening phenomena in ductile sheet metal. Exp Mech 54(08):1355-1371. https://doi.org/10.1007/s11340-014-9900-4

[23] Tao H, Zhang N, Tong W (2009) An iterative procedure for determining effective stress-strain curves of sheet metals. Int $J$ Mech Mater Des 5(01):13-27. https://doi.org/10.1007/s10999-008-9082-2

[24] Mei H, Lang LH, Liu KN, Yang XG (2018) Evaluation Study on Iterative Inverse Modeling Procedure for Determining Post-Necking Hardening Behavior of Sheet Metal at Elevated Temperature. Metals 8(12):1044. https://doi.org/10.3390/met8121044 [25] Dong GJ, Zhao CC, Cao MY, Hao HB (2010) Experimental research on lateral pressure coeficient of solid granules medium under high pressure. Journal of Plasticity Engineering 17(03):124-128. 
Figures

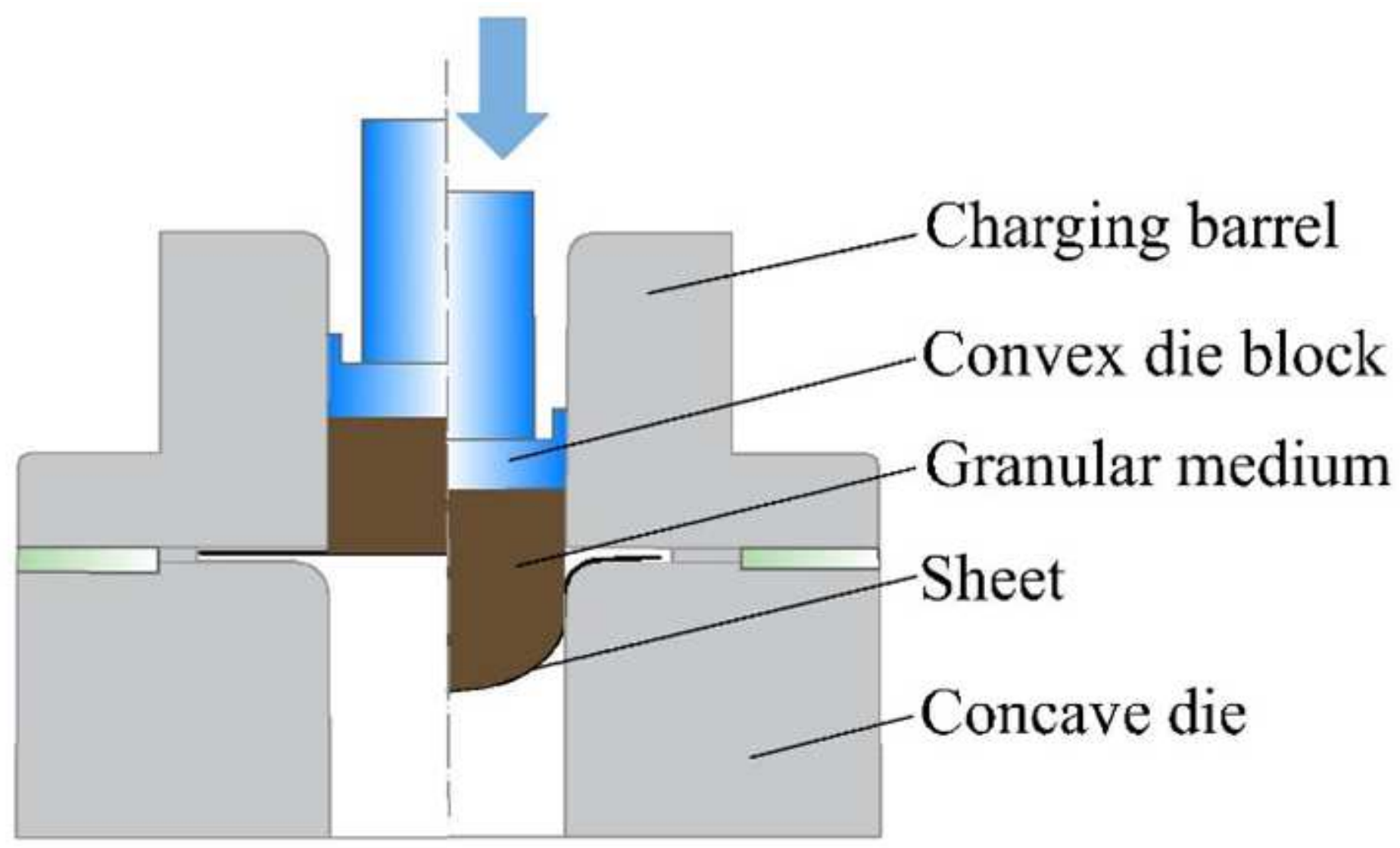

Figure 1

Schematic of granular medium forming process

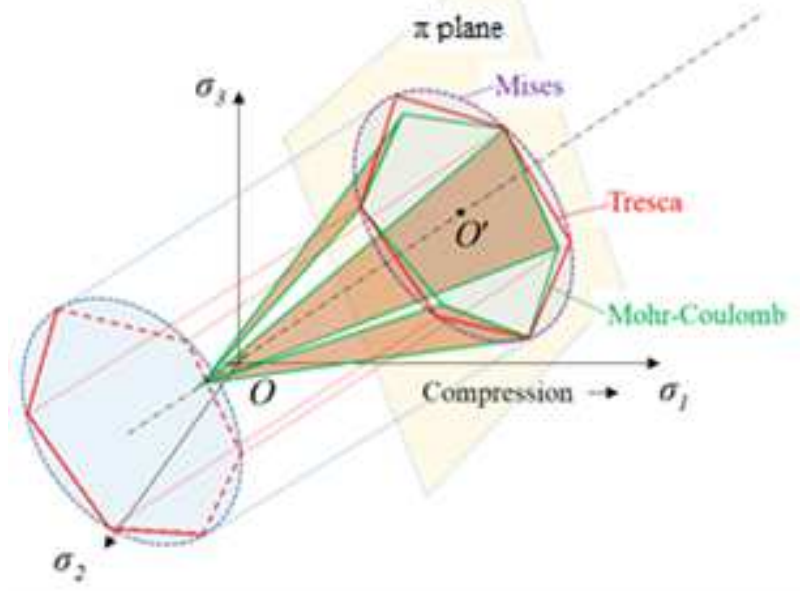

Figure 2

Mohr-Coulomb yield surface in 3D stress space 


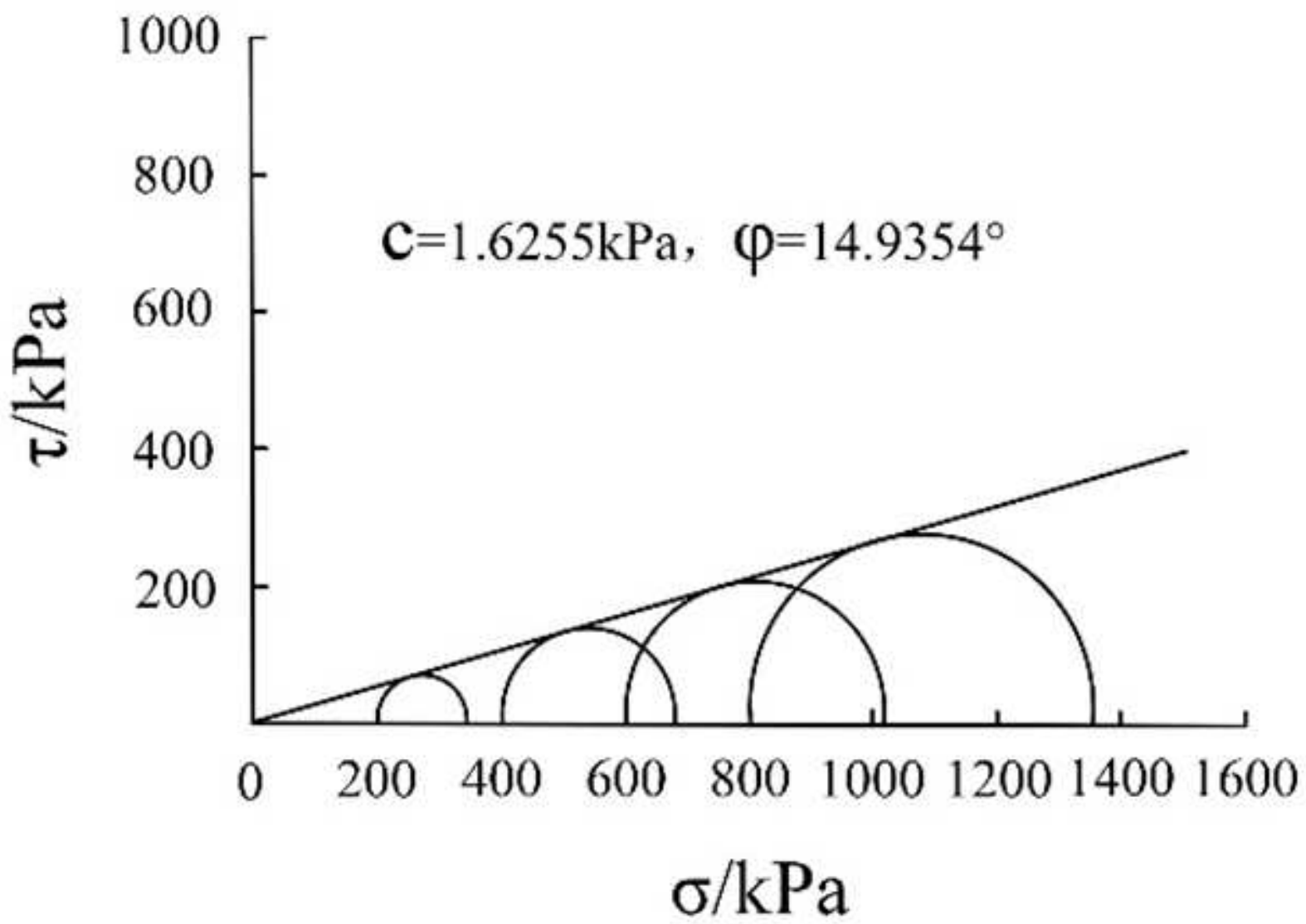

Figure 3

Result of triaxial compression tests 
Get the result of $\left\{P_{i}^{e x}, U_{i}^{e x}\right\}$

by tensile test

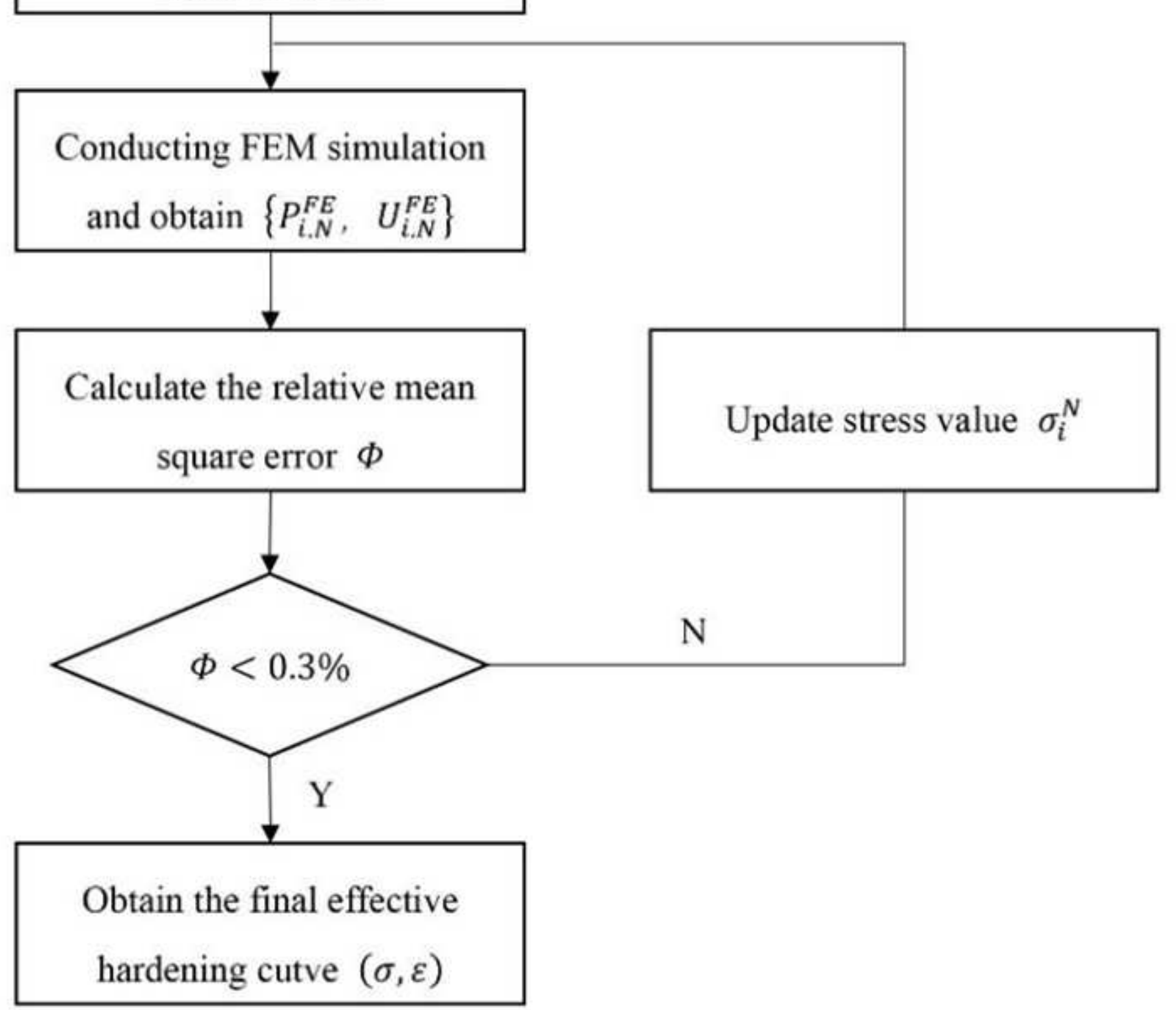

Figure 4

Schematic diagram of the inverse method[24] 


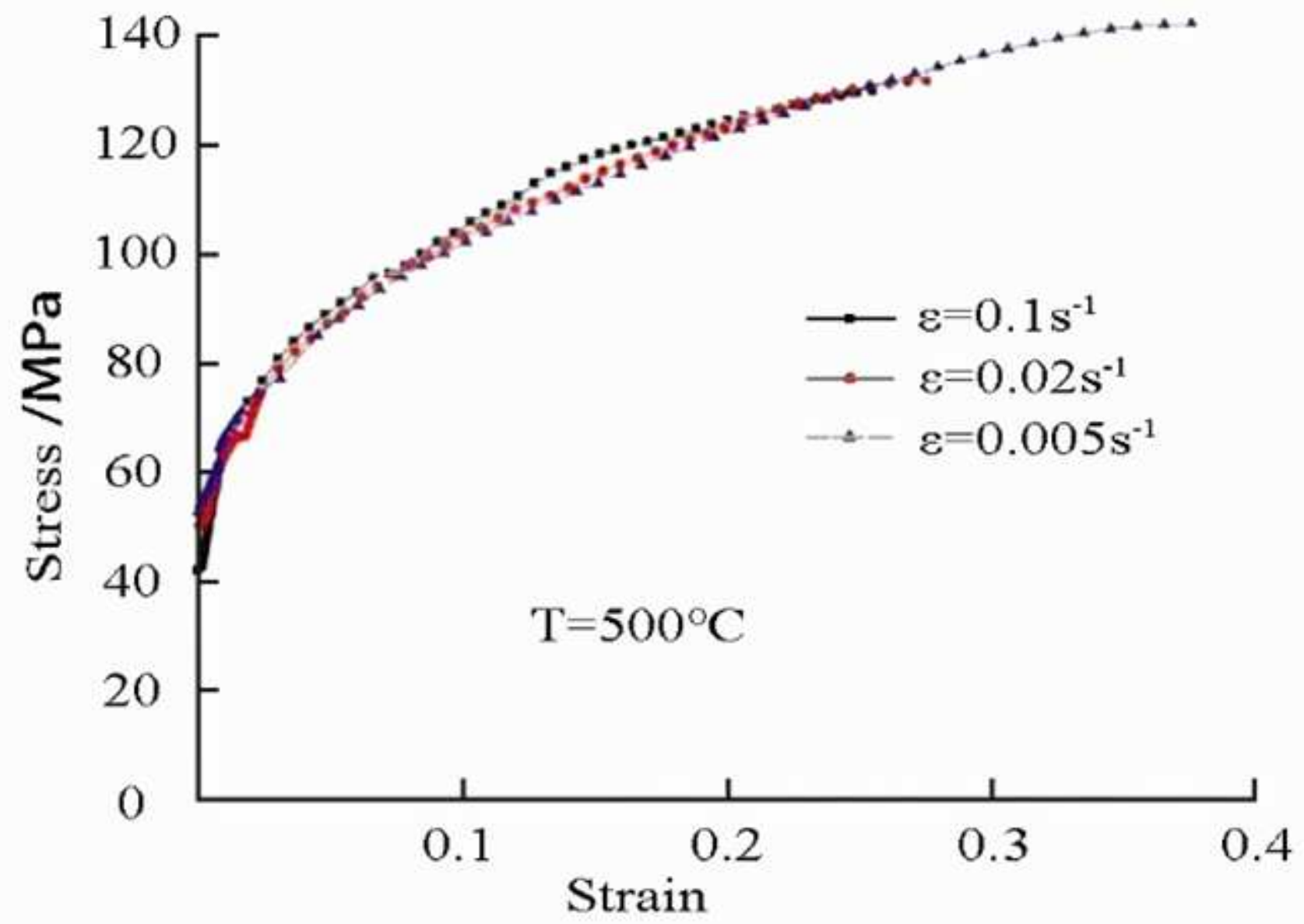

Figure 5

True stress-strain curves of TA1 sheet under different conditions 


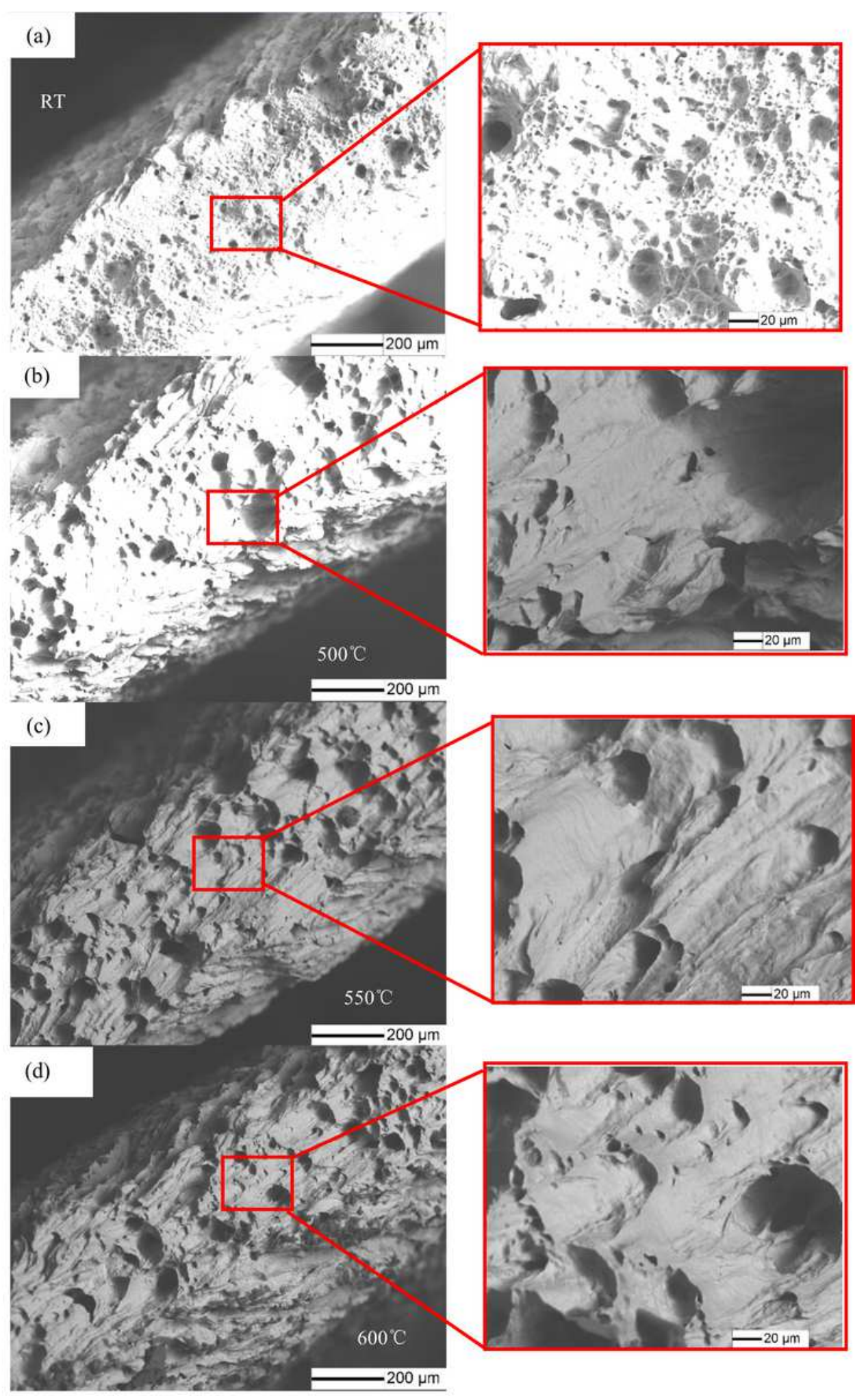

Figure 6

Fracture morphology of TA1 specimen after tensile test 


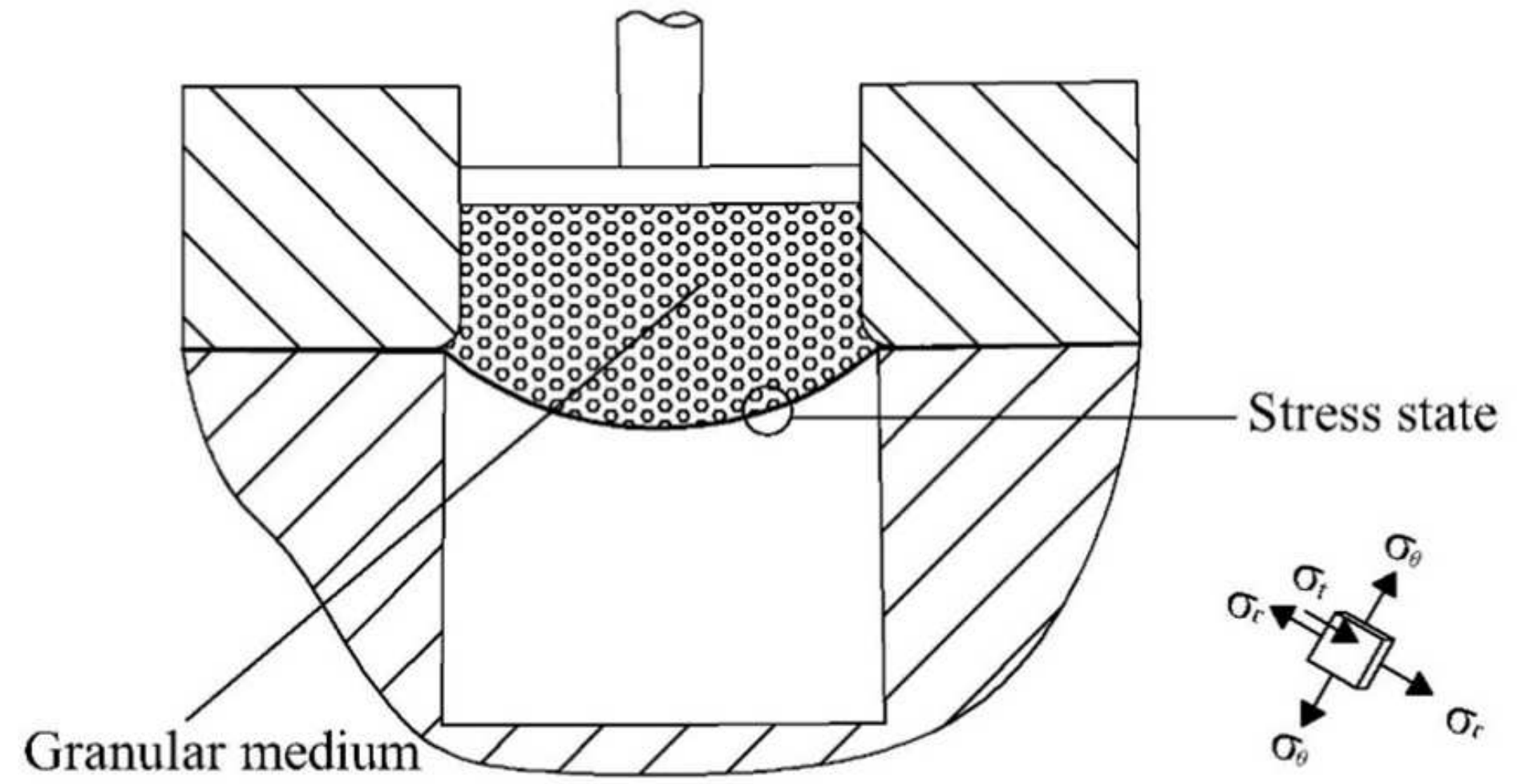

Figure 7

Diagram of the process of deep drawing with granular medium

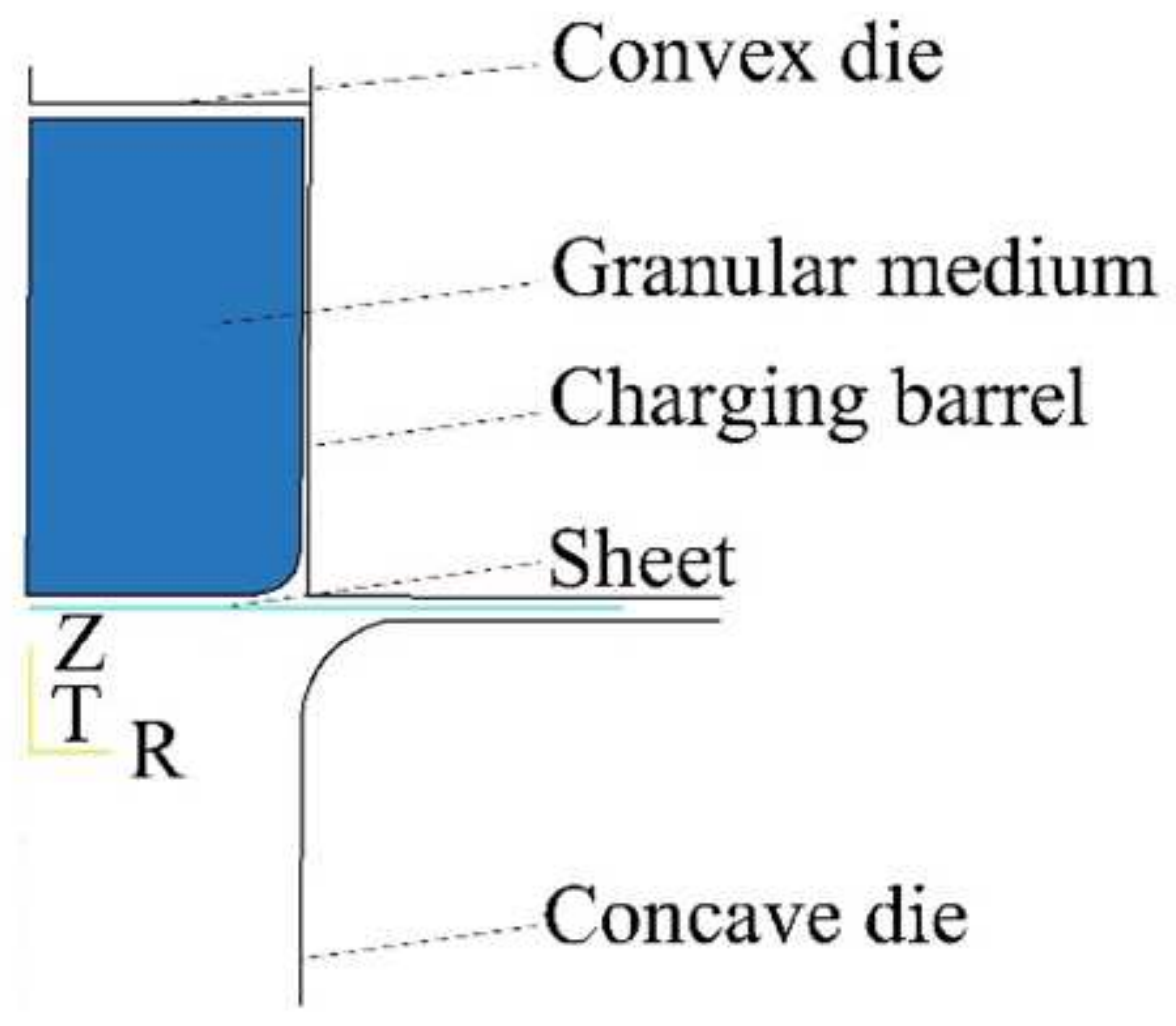

Figure 8 
Numerical model of the granular medium forming process
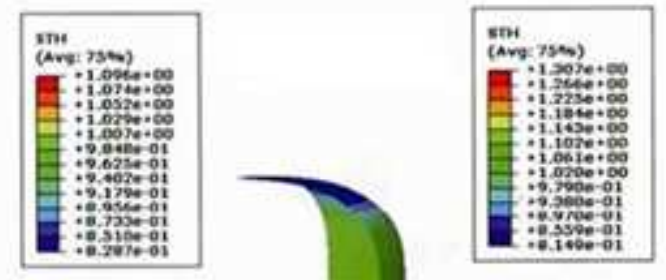

$D=180 \mathrm{~mm}$

$H=44 \mathrm{~mm}$

\section{$D=180 \mathrm{~mm}$ \\ $H=81 \mathrm{~mm}$}

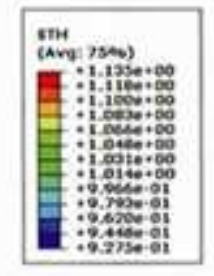

$D=160 \mathrm{~mm}$

$H=42.5 \mathrm{~mm}$

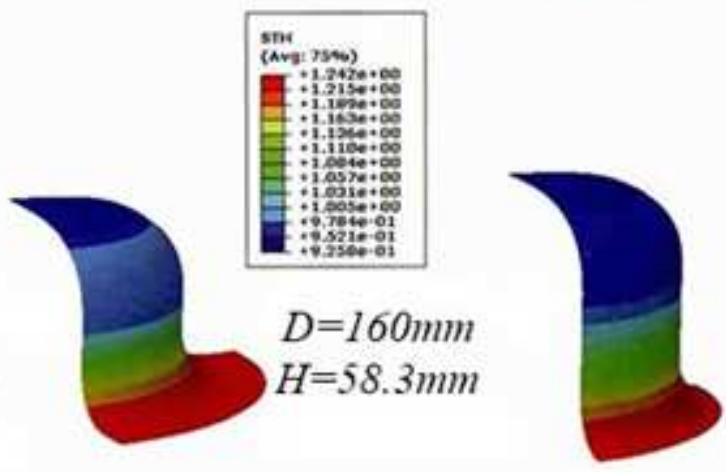

Figure 9

Results of numerical simulation

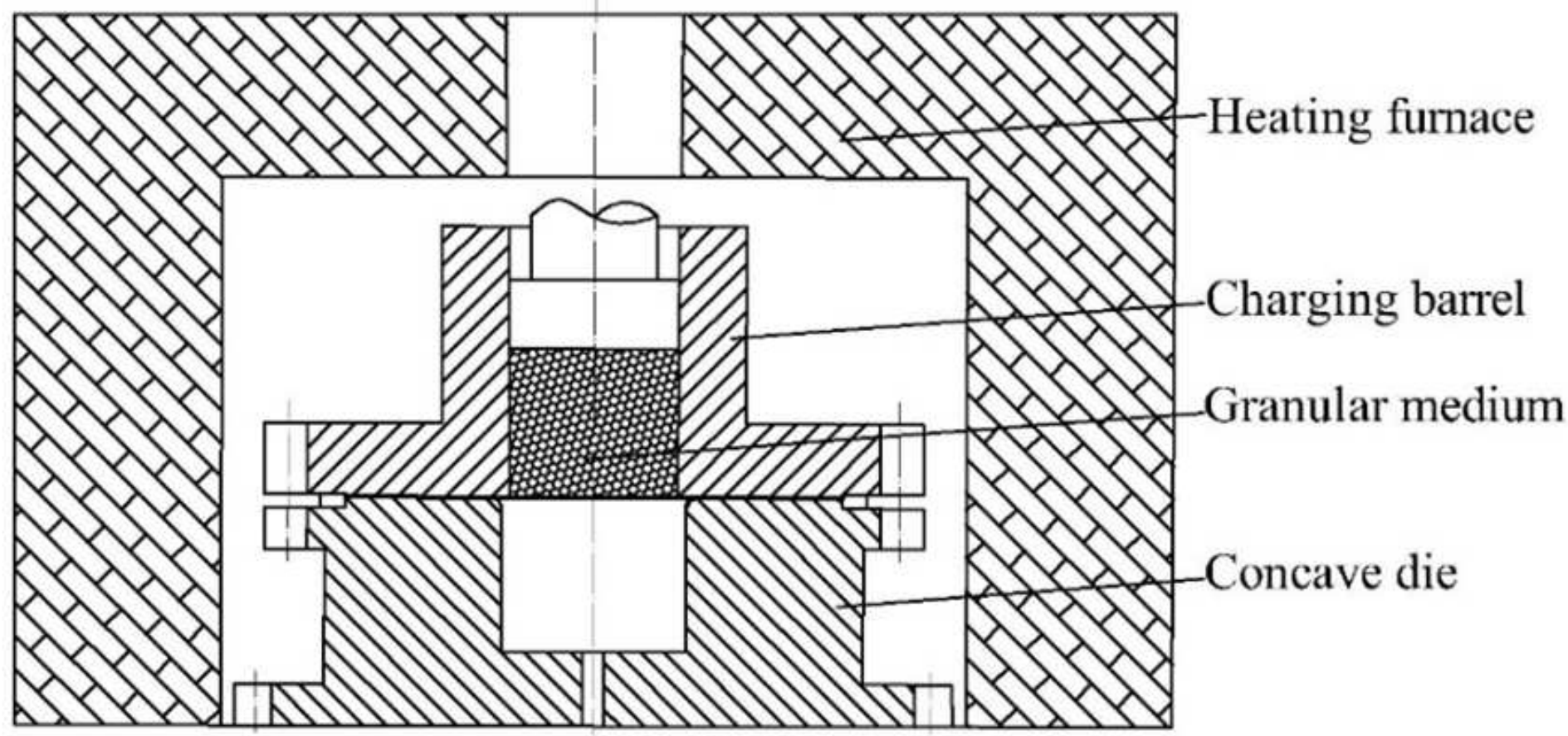

Figure 10

Diagram of experimental equipment for hot granular medium forming 


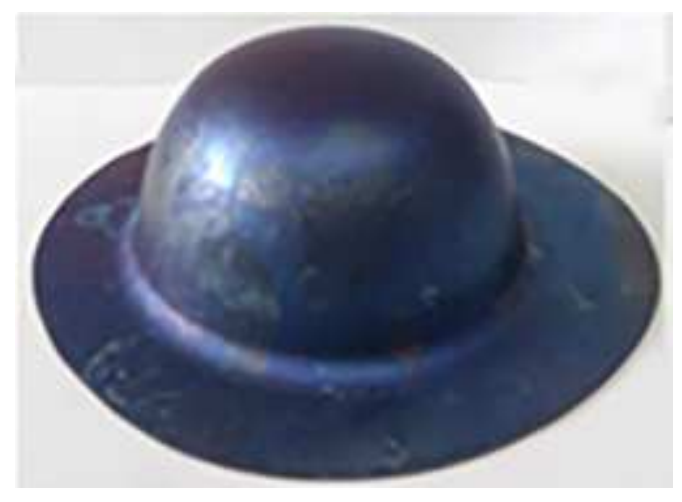

\section{Figure 11}

Fabricatd TA1 part by GMF method at 500区

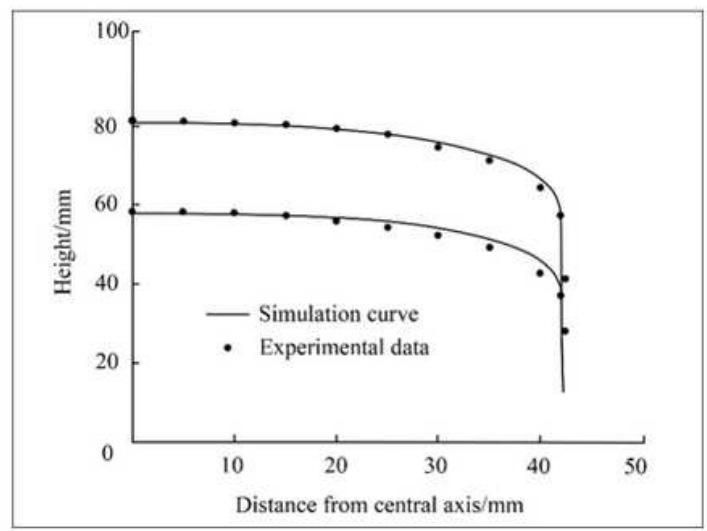

(a)

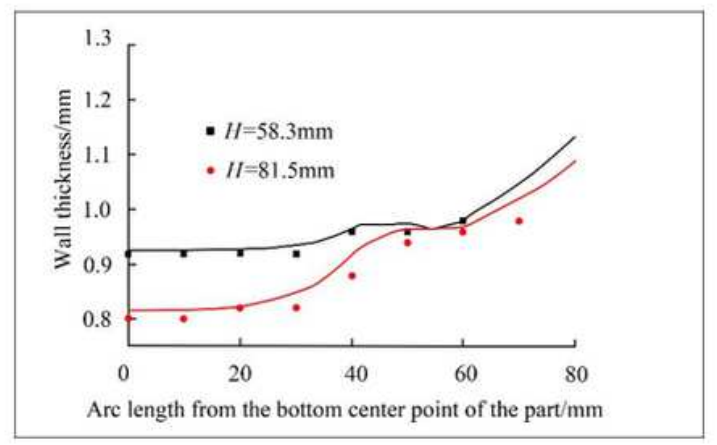

(b)

\section{Figure 12}

Comparison of shape dimension and thickness distribution between numerical simulation and experimental results (a) Comparison of shape dimension between numerical simulation and experimental results (b) Comparison of thickness distribution between numerical simulation and experimental results 